\title{
Polishing resistance of polymer concrete pavement using limestone aggregate
}

\author{
Shyue Leong Lee, Mohammad Abdul Mannan and Wan Hashim Wan Ibrahim
}

Department of Civil Engineering, Universiti Malaysia Sarawak, Kota Samarahan, Malaysia

\begin{abstract}
The purpose of this research was to investigate the polishing resistance of uncoated and resin-coated specimens under polishing and chemical attack. Low-quality aggregate, limestone and orthophthalic unsaturated polyester resin were the main materials. From the analysis, the macrotexture was reduced from the coarser aggregate to finer aggregate mix proportion. Resin-coated specimen was more polishing resistant than the uncoated specimen. Thickness reduction for resin-coated specimen was $1.8 \%$ after $9 \mathrm{~h}$ polishing, while the thickness reduction for uncoated specimen was $1.9 \%$ after $6 \mathrm{~h}$ polishing. In comparison with the uncoated specimen, the British pendulum number (BPN) of resincoated specimen under dry and wet conditions was $8 \%$ higher and $16 \%$ lower, respectively. For the chemical resistant investigation, the immerging mediums used were water, sulphuric acid, sodium chloride, sodium hydroxide and used engine oil. The uncoated and resin-coated specimens were immersed into the solutions under direct immersion as well as wetting and drying for 24 weeks. Sulphuric acid and sodium hydroxide affected the BPN on both uncoated and resin-coated specimens but not for water and used engine oil, while sodium chloride only affected the BPN of the uncoated specimen.
\end{abstract}

\section{ARTICLE HISTORY}

Received 12 February 2018

Accepted 10 June 2018

\section{KEYWORDS}

Microtexture; macrotexture; polishing; friction; skid resistance

\section{Introduction}

Friction is a force of resisting motion which is generated at the interface between tyres and the surface of pavement (asphalt concrete pavement and Portland cement concrete pavement). With this friction, driver is able to control their vehicles. The term 'coefficient of friction' is describing the force divided by the vertical load (Roe et al. 1998). As for the term 'skid resistance', signified the degree of friction which is attributed by the road surface itself (Roe et al. 1998, Malal et al. 2013) and it generally refers to the wet condition of the road surface (Roe et al. 1998, NASEM 2009). Moreover, skid resistance is included in the design of highway geometric because it is an important parameter for road safety (NASEM 2009, Malal et al. 2013).

Skid resistance is primarily affected by microtexture and macrotexture. Both of these textures are the most important (Ibrahim 2007) and affect the accident rates (Ibrahim 2007, NASEM 2009, Filippo and Armando 2017). For example, the higher accident rate is due to low skid resistance (Ibrahim 2007, Dan et al. 2015). As such, skidding on wet pavement can be reduced by maintaining the pavement in a high level of microtexture and macrotexture (Henry 2000). Maintaining the pavement surface back to the accepted level of microtexture and macrotexture had been proven in wet crashes reduction. Therefore, microtexture and macrotexture can be used as an indicator in skid resistance evaluation (Marta et al. 2016). Thus, microtexture and macrotexture are very crucial factors in affecting the skid resistance.

There are several factors affecting the microtexture of aggregate and macrotexture of the pavement surface. For microtexture, it is affected by the physical properties and mineralogy of the aggregate, asphalt content, traffic volume and seasonal variation. Skid resistance is affected by traffic volume and the effect of commercial vehicles was more severe (Eyad et al. 2009). Moreover, physical properties of aggregate such as hardness, shape, angularity, polishing resistance, surface texture, mineralogy composition, abrasion resistance and soundness of the aggregate are very important for microtexture (NASEM 2009, Bo et al. 2017). As such, the selected material must have the ability to withstand polishing under the traffic load and environmental effects (NASEM 2009). In the mineralogical aspect, aggregate has high polishing resistance because it consisted of hard, strongly bonded and interlocking mineral crystal (coarse grains) (Malal et al. 2013). Furthermore, skid resistance is also affected by seasonal variation. The friction is lower in spring and summer, and higher in autumn and winter (Subhi and Farhad 2005, Ibrahim 2007).

Macrotexture is affected by several factors namely, the aggregate grading, size, shape and construction techniques on asphalt concrete pavement and concrete pavement (Eyad et al. 2009, NASEM 2009, Ignacio et al. 2012, Marta et al. 2016, Bo et al. 2017). Asphalt concrete produced from different mix proportions influenced the skid resistance due to different morphology of the produced pavement surface (Fwa et al. 2003, Subhi and Farhad 2005, Bo et al. 2017). The size and shape of aggregate varied the volumetric properties of asphalt concrete and also the asphalt content. This directly changed the surface morphology of pavement (Subhi and Farhad 2005). Furthermore, ravelling occurred due to inappropriate use of asphalt grade without considering the regional weather. This led to the change of pavement surface and skid resistance of pavement (NASEM 2009). 